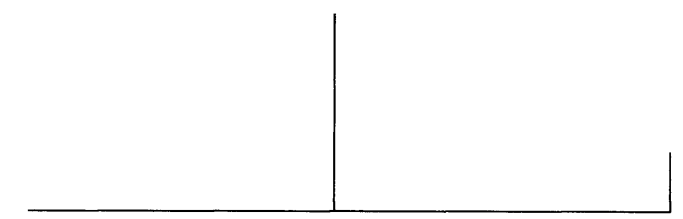

Rev. Latinoam. Psicopat. Fund., X, 2, 295-306

\title{
Você pode viver com as vozes em sua cabeça?*
}

Daniel B. Smith

Ângelo, um cientista londrino pela casa dos trinta, de cabelos castanho-avermelhados, óculos de metal redondos e uma leve e discreta gagueira, relembra vividamente o dia em que começou a ouvir vozes. Foi no dia 7 de janeiro de 2001; ele tinha acabado de fazer os exames orais de seu doutoramento em química em uma universidade americana, onde havia conduzido pesquisa sobre eletromagnetismo na faixa do infravermelho nos quatro anos e meio anteriores. Ângelo ia a pé do laboratório para casa quando, de repente, ouviu duas vozes. "Era como ouvir pensamentos que não eram meus em minha cabeça", explicou ele recentemente. "Elas se identificaram como Andrew e Oliver, dois anjos. Com os olhos da mente, eu podia ver a imagem de um homem careca, de meia-idade, vestido de branco contra um fundo branco. Este, me disseram, era Oliver." Para horror de Ângelo, os anjos disseram que, nos dias seguintes, ele morreria de hemorragia cerebral. Aterrorizado, Ângelo correu para seu apartamento e se trancou lá. Por três longos dias aguardou seu destino. No quarto dia, seu orientador levou-o ao hospital local, onde Ângelo foi admitido na ala psiquiátrica. Nunca antes ele havia estado sob cuidados psiquiátricos. Nunca ouvira vozes antes. O diagnóstico foi esquizofrenia com traços depressivos.

* Publicado originalmente no New York Times, 25 de março de 2007, p. 1-10.

Tradução de Monica Seincman. 


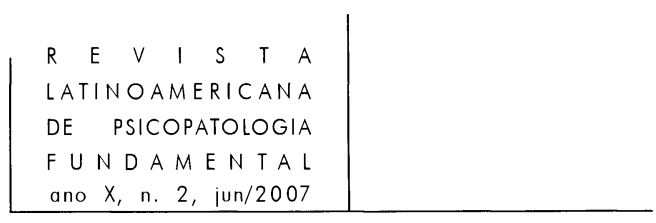

Ângelo lembra-se da estada no hospital como um terrível pesadelo. No auge da confusão natural e do medo ante o estraçalhamento de sua estabilidade psicológica, Ângelo não reagiu bem ao antipsicótico que lhe foi prescrito. A risperidona deveria aliviar os sintomas de esquizofrenia por reduzir o nível de dopamina no cérebro. No caso de Ângelo, os comprimidos tiveram, sobretudo, um efeito negativo. As vozes continuaram fortes e perturbadoras - uma presença inabalável, quietas somente durante o sono -, enquanto ele permanecia apático e debilitado. "Se você pensar a mente como uma corrente de pensamentos", disseme ele em um e-mail, "a droga tornou minha mente lenta como um rio de melado." Depois de vários dias internado, os pais de Ângelo voaram dos Estados Unidos para Londres e levaram-no para casa.

Mais de seis anos depois, Ângelo ainda vive na casa dos pais. Ele toma regularmente um coquetel de antidepressivos e antipsicóticos, com efeitos adversos toleráveis, e vê um psicólogo a cada dois meses para monitorar a medicação. Os comprimidos ajudam-no a controlar as vozes, mas não são capazes de erradicá-las. Pouco depois de voltar de Londres, ele tentou retomar sua carreira, aceitando um posto de pesquisa na universidade em que se graduou. Ele ficou oito meses (seus vizinhos ouviram-no gritar com suas vozes e chamaram a polícia), internou-se no hospital por seis semanas e voltou para casa. Apesar destas recaídas, Ângelo manteve seu otimismo. Ele quer muito descobrir novas formas para combater as vozes. Não faz muito tempo, ele encontrou uma. Em novembro, seu psicólogo o informou sobre um grupo de apoio local para pessoas que ouvem vozes, do qual achou que Ângelo poderia se beneficiar. Ele começou a participar desse grupo no final do ano passado. Eu o vi pela primeira vez em um encontro do grupo em meados de janeiro (fui autorizado a observar com a condição de não divulgar os sobrenomes dos participantes), que aconteceu em uma sala iluminada e cuidadosamente decorada do centro de saúde mental de uma comunidade em North Finchley, um subúrbio rico e verde ao norte de Londres. O grupo era pequeno, mas eclético. Além dos facilitadores - Jo Kutchinsky, um terapeuta ocupacional, e Liana Kaiser, uma estudante de serviço social -, cinco homens e mulheres reuniam-se em um círculo de cadeiras forradas e pesadas em torno de uma velha mesa de café. Além de Ângelo, estavam Stewart, um jovem trabalhador londrino com cabeça raspada e um brinco de argola; Jenny, uma mulher afável na casa dos cinquienta, que falava sobre seu gosto pelas artes e artesanatos; Michelle, uma mulher atarracada que dominava a sessão com opiniões enérgicas; e David, um homem de seus sessenta anos, com uma barba grisalha densa e um cabelo de pajem, que despencou de seu lugar e cochilou durante grande parte do encontro.

Ângelo era o mais novo no grupo - era sua terceira visita - e não parecia inclinado a participar totalmente. Quando Kutchinsky abriu o encontro pedindo 


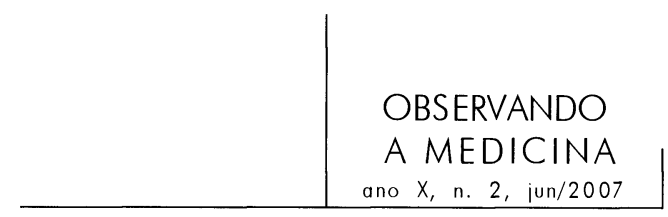

a cada membro que discutisse a experiência de ouvir vozes vivida na semana anterior, ele mencionou de passagem que as vozes haviam tornado a leitura custosa para ele; e rapidamente passou o bastão. O que se seguiu foi, por vezes, doloroso. Stewart, em particular, estava visivelmente agitado. Sua vida alucinatória, como ele a descreveu, era caótica e irreprimível. Ele ouviu vozes que pediram socorro; vozes de estranhos; a voz de seu pai. Algumas vezes, ouviu também vozes de comandos militares, que se ofereciam para defendê-lo da confusão. "Faz tempo que não tenho me sentido bem", disse ele, sombriamente. A maioria dos membros fala de suas vozes do mesmo modo que os comediantes falam de suas sogras: opressivas e irritantes, mas uma parte inevitável da vida com a qual também se deve aprender a conviver. Quando seu nome foi chamado, David levantou a cabeça e falou sobre sua luta para aceitar as vozes como parte de sua consciência. "Aprendi com o tempo que minhas vozes não podem ser rejeitadas", disse ele. "Não importa o que eu faça, elas não vão embora. Tenho de encontrar um jeito de viver com elas." Jenny falou sobre como se manter ocupada acalmou suas vozes; ela parecia ter seguido um número notável de cursos para adultos. Michelle expressou sua crença de que suas vozes não eram mais exóticas do que pensamentos poderosamente negativos. "Os pensamentos negativos são universais", disse ela. "Todos os têm. Todos. O que importa é como você se relaciona com eles; é isto que interessa."

Foi difícil avaliar a reação de Ângelo ao longo dos testemunhos. Por isso, puxei-o para o meu lado e perguntei o que ele estava achando. "É interessante ouvir as histórias das pessoas", disse ele. "Antes de começar a vir, eu não percebia a dimensão do sofrimento de algumas pessoas. Ouço vozes há seis anos. Algumas pessoas ouvem há 15 ou vinte anos. É impressionante." Perguntei-lhe se a informação o acalmava ou o aterrorizava. "É um pouco assustador, de certa forma. Acho que posso ficar assim por muito tempo." Mesmo assim, ele parecia apreciar a camaradagem. Por anos, ele havia ficado socialmente isolado. Passava a maior parte de seu tempo com seus pais e uma simpática irmã mais velha. Seus vizinhos sabiam apenas que ele "não trabalhava". Era reconfortante, disse ele, finalmente falar com pessoas que o entendiam.

O encontro a que assisti em Londres é um entre dezenas de similares afiliados a uma organização pequena, mas influente e bem-enraizada conhecida como Rede dos que ouvem vozes (Hearing Voices Network, HVN). Sediada em Manchester, a Rede desenvolveu, desde a criação, em 1991, uma variedade de serviços relacionados ao fenômeno conhecido como alucinação auditiva: uma linha direta para pessoas que sofrem com a experiência; oficinas educacionais para profissionais da saúde mental; e 170 grupos de apoio em toda a Grã-Bretanha, com outros mais em organização. A rede desafia abertamente a relação psiquiátrica padrão - de um lado, o médico especialista; de outro, o paciente psicótico -; e 


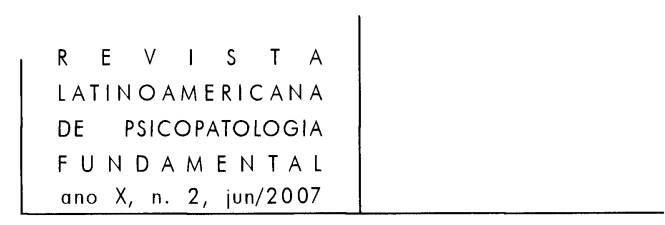

dela pode-se dizer que leva o movimento de defesa do consumidor no cuidado da saúde mental o mais longe possível. Apesar de os grupos da HVN se encontrarem em diversos contextos - dos hospitais psiquiatricos às igrejas e às sedes da organização - tudo deve ser feito por quem ouve vozes, ou deve haver planos para que venha a ser assim. Além disso, os grupos da HVN devem aceitar todas as interpretações sobre alucinações auditivas como igualmente válidas. Se alguém vem a um grupo e se queixa que ouve a voz da rainha da Inglaterra, e se a pessoa acha útil crer nisso, nenhuma tentativa será feita para contradizê-la; o que se buscará no grupo é descobrir o que isso significa para ela.

A abordagem ecumênica faz com que a HVN seja uma organização difícil de definir. Conheci membros que acreditavam serem suas vozes resultado de defeito bioquímico, que requeriam, por isso, todas as armas que a farmacologia moderna tem a oferecer; outros acreditavam que suas vozes eram sinais do reino espiritual - uma dádiva a ser cultivada. No entanto, a retórica mais clara da organização é oposicionista e antipsiquiátrica.

Por mais de meio século as alucinações auditivas foram estudadas e discutidas primariamente no quadro de uma doença mental severa, mais especificamente esquizofrenia, e relacionada a delírios bizarros, pensamento confuso e dissociação emocional. Aproximadamente $75 \%$ dos pacientes diagnosticados com esquizofrenia ouvem vozes, e para a maioria a experiência é irrefutavelmente negativa. As vozes podem emitir comandos, comentar sarcasticamente as ações cotidianas ou censurar, amaldiçoar e insultar quem as ouve. Um terço das pessoas com esquizofrenia tenta o suicídio; um quinto ouve vozes que ordenam a agir assim. A rede não discorda que alucinações auditivas são freqüentemente dolorosas: muitos dos membros que dirigem a organização toleraram vozes que os atormentavam; vez por outra, procuraram ajuda psiquiátrica.

Do que a rede sim discorda é que a angústia psicológica causada por ouvir vozes indica uma doença mental abrangente. Mas a espinha dorsal do argumento da HVN contra a psiquiatria apresenta duas posições principais. A primeira é que muitas pessoas ouvem vozes, e ouvem muito mais tipos de vozes do que se presume usualmente. A segunda é que a alucinação auditiva - ou "o ouvir vozes (voice-hearing)", alternativa mais neutra preferida pela rede - deve ser considerada não um fenômeno patológico que precisa ser erradicado, mas uma experiência significativa, interpretável, intimamente ligada à história de vida de quem as ouve e, mais comumente do que o contrário, a traumas pessoais não resolvidos. Em 2005, Louise Pembroke, membro proeminente da HVN, propôs um Dia Mundial dos que Ouvem Vozes (previsto para 2008), que vai "desafiar as atitudes negativas em relação às pessoas que ouvem vozes baseadas na incorreta suposição de que isso em si é sinal de doença, uma suposição que não 
é baseada em suas próprias experiências e que estigmatiza, isola e torna as pessoas doentes".

A insistência da Rede de que não apenas o psicótico ouve vozes não contradiz a ortodoxia psiquiátrica. De acordo com o Manual de Diagnóstico e Estatística dos Transtornos Mentais (o DSM-IV, nota do E.), tido como a bíblia da psiquiatria, as alucinações auditivas são apenas um sintoma potencial de doença mental - elas devem aparecer com outros sintomas, persistir por uma duração específica de tempo e impedir o funcionamento no dia-a-dia para se tornar parte de uma síndrome diagnosticável. Em um debate ocorrido em 2001 sobre se as vozes são, por definição, patológicas, Tony David, neuropsiquiatra do Instituto de Psiquiatria em Londres, observou que "alguém que ouve vozes e não está em sofrimento, que vive uma vida frutífera e produtiva de acordo com o critério do senso comum, nunca entraria na arena em que a possibilidade da doença mental estivesse em discussão". Tampouco a psiquiatria insiste em que a síndrome em questão, na qual um ouvinte de vozes está em sofrimento, seja invariavelmente esquizofrenia. Aproximadamente $20 \%$ dos pacientes que sofrem de mania e $10 \%$ dos que sofrem de depressão ouvem vozes. Alucinações auditivas podem também ser causadas por condições "orgânicas", como Parkinson, Alzheimer, epilepsia lobo-temporal, hipertireoidismo e enxaquecas, e há muito se sabe que ocorrem na passagem entre o sono e o despertar completo.

Já a insistência da HVN em que ouvintes de vozes devem prestar muita atenção ao que dizem suas alucinações está longe do tradicional. Exposição prolongada à psicose não tratada é tida por muitos especialistas como prejudicial à habilidade do indivíduo de manter seu trabalho ou uma relação significativa; por outros especialistas, como danosa à função cerebral - o que os clínicos chamam de "toxicidade psicossocial" e "neurotoxicidade", respectivamente. E apesar de os psiquiatras reconhecerem que quase todos são capazes de alucinar uma voz sob certas circunstâncias, eles insistem que as alucinações que ocorrem com as psicoses são qualitativamente diferentes. "Não se pode enfatizar demasiadamente o conteúdo das alucinações", diz Jeffrey Lieberman, chefe do departamento de psiquiatria na Universidade de Columbia. "Ao estabelecer o diagnóstico correto, é importante focar nos sinais e nos sintomas" de um determinado transtorno. Ou seja, é essencial determinar como as vozes se manifestam. Vozes que falam na terceira pessoa, ecoam os pensamentos de um paciente ou fornecem um comentário rápido sobre suas ações são consideradas classicamente indicativas de esquizofrenia.

Interpretar vozes em relação ao passado de um paciente tem uma história de altos e baixos no tratamento da psicose. Apesar de Freud haver desencorajado a aplicação da psicanálise a pacientes psicóticos, ela se tornou, nos 25 anos após a Segunda Guerra Mundial, um tratamento largamente difundido para a 


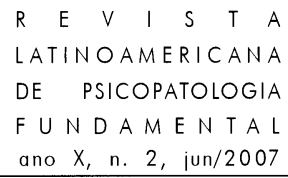

esquizofrenia no mundo de língua inglesa. Esse episódio em psiquiatria é agora amplamente reconhecido como um desastre médico e moral; psicoses incapacitantes eram normalmente atribuídas a mães insuficientemente provedoras e "esquizofrenogênicas". "A abordagem psicanalítica da psicose era tóxica", diz Peter Weiden, um professor de psiquiatria do Centro Médico State University of New York no Brooklin. "Os médicos de então estavam com freqüência em profundo antagonismo com os membros da família. Eles culpavam os pais, deixavam-nos de fora do processo de tratamento e isolavam o paciente de sua família." Nos últimos trinta anos, o modelo biomédico substituiu o psicanalítico, apoiado nos avanços na farmacologia, na pesquisa genética e neurológica; e na realização de estudos empíricos de larga escala que concluíram que a psicanálise foi, na melhor das hipóteses, inútil e, na pior, ativamente destrutiva. Hoje, a medicação é normalmente prescrita para extinguir, ou no mínimo atenuar, as vozes (aproximadamente $80 \%$ dos pacientes experimentam uma redução nas vozes, diz Weiden, apesar de isto nem sempre se traduzir em igual melhora no funcionamento do dia-a-dia); a psicoterapia é normalmente aceita como adjuvante, para lidar com as questões do funcionamento social e do estigma.

Há sinais, contudo, de que a psicoterapia está novamente invadindo os limites do paradigma biomédico no tratamento das psicoses. Desde a década de 1990, um número crescente de pesquisadores e clínicos, predominantemente ingleses, compara a audição de vozes nos pacientes psicóticos com a audição de vozes em não pacientes, medindo a incidência de alucinações na população em geral, e usando a terapia cognitivo-comportamental, um tratamento popular de curto prazo para depressão e ansiedade, que os auxilia a controlar suas respostas às vozes que continuam a ouvir. A TCC normalmente pede para os pacientes investigarem minuciosamente como eles interpretam seus sintomas em vez de focar na doença como uma causa subjacente. "A questão de saber se é efetiva, e em que extensão", diz Lieberman, "ainda está sendo investigada". Até agora, o uso da TCC no tratamento das psicoses é muito mais prevalente no Reino Unido do que nos Estados Unidos. Em grande parte, diz Lieberman, é porque "a motivação para pesquisar o tratamento veio majoritariamente dos investigadores ingleses". Mas, acrescenta, "você também pode ler isto dentro do contexto da influência de um forte movimento antipsiquiátrico e antimedicamentoso na Inglaterra - há mais do que um interesse em chegar a um tratamento nãomedicamentoso no uso clínico".

$\mathrm{Na}$ Inglaterra, a nova abordagem cognitiva da psicose e os esforços da HVN são independentes um do outro, e algumas vezes opostos. Por exemplo, os que a lideram criticam freqüentemente até pesquisadores acadêmicos simpáticos a eles por serem insuficientemente políticos. Ambas as abordagens compartilham o propósito similar em procurar colocar o ouvir vozes no contínuo da experiência 


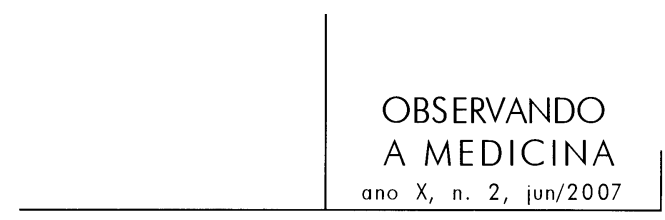

humana normal - uma, para melhor tratar os pacientes; outra, firmemente convencida de que o ouvir vozes não precisa interferir com uma vida também "normal". Ao longo dos anos, eles forjaram algo como uma aliança; psicólogos, apesar de não abraçarem as posições mais polêmicas da HVN, freqüentemente indicam os grupos a seus pacientes; a HVN, por seu lado, freqüentemente cita a pesquisa dos psicólogos cognitivos. Ambos, a ROV e a abordagem cognitiva da psicose podem ser ligadas, em vários graus, à mesma figura radical.

Quando a Rede é acusada de hostilizar a psiquiatria, seus membros apontam por vezes que a organização foi, com efeito, fundada por um psiquiatra - ainda que um singularmente não ortodoxo psiquiatra. Em 1986, Marius Romme, professor na Universidade de Maastricht, nos Países Baixos, recebeu uma paciente, Patsy Hage, que sofria de alucinações auditivas crônicas e caiu em uma profunda depressão suicida. Patsy obteve conforto somente ao ler A origem da consciência no colapso da mente bicameral, um livro excêntrico, publicado em 1976, por Juilian Jaynes, psicólogo de Princeton, no qual afirma que antes de 2000 a.C., todos os seres humanos eram guiados por comandos verbais alucinados causados por uma cisão física entre os hemisférios direito e esquerdo do cérebro.

Romme se perguntou se Hage poderia se beneficiar de comunicar essa teoria a outros que ouviam vozes e conseguiu aparecer em um programa de TV popular na Holanda. Eles pediram a pessoas que ouviam vozes para entrar em contato: 450 pessoas ligaram, um terço das quais dizendo que eram capazes de viver com suas vozes sem maiores dificuldades. $O$ fato de que esse pequeno grupo, cuja existência o surpreendeu, ter servido como um recurso terapêutico impressionou Romme. Ele pediu a vinte homens e mulheres que haviam aprendido a conviver com suas vozes para serem oradores em uma conferência para ouvintes de vozes. O princípio predominante do encontro era que todas as interpretações do ouvir vozes, por mais incomuns que fossem, seriam aceitas.

Hoje, os membros da HVN falam sobre aquela primeira conferência como o momento de nascimento de sua organização - e, certamente, de um movimento mundial de Ouvintes de Vozes. Atualmente há organizações de auto-ajuda para pessoas que ouvem vozes em mais de 15 países, incluindo Alemanha, Japão e Austrália (apenas recentemente o grupo começou incursões nos Estados Unidos). Enquanto isso, Romme apareceu como um líder ativista inspirado, cada vez mais falando sobre a psiquiatria em termos de opressão cultural e pessoal. As pessoas que ouvem vozes, declarou ele, "são como os homossexuais nos anos 1950 necessitam de libertação e não de cura”. A HVN com freqüência ecoa esta postura de protesto. Suas conferências anuais, que acontecem em Manchester, projetam um tom antiestablishment. Ron Coleman, um proeminente membro, traz uma tatuagem onde se lê "Psicótico e Orgulhoso" e espera o dia em que ele "poderá andar pelas ruas falando com as vozes sem ter a liberdade negada". 


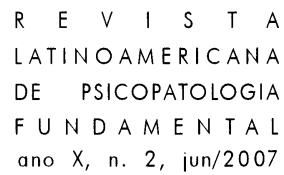

No material que divulga publicamente, contudo, a HVN tende a focar menos na retórica de Romme e mais em sua pesquisa. Em um artigo publicado com um grupo de colegas em The Journal of Nervous and Mental Diseases em 1998, Romme apresentou um trabalho sobre alucinações em três grupos: pacientes com esquizofrenia, pacientes com transtorno dissociativo e não-pacientes. Todos os três grupos ouviram uma mistura de vozes positivas e negativas (apesar de os pacientes terem ouvido mais vozes negativas do que os não-pacientes), apresentaram experiências traumáticas em seu passado e ouviram vozes internas e externas. O que para Romme mais distinguia as vozes dos pacientes das dos não-pacientes era que os últimos acreditavam ter controle sobre suas vozes; eles raramente procuravam se livrar delas ou ignorá-las e encontravam modos de conversar com elas e entendê-las. "Ajudar o paciente a aceitar as vozes e ativamente desenvolver com eles estratégias efetivas para lidar com elas", Romme havia observado antes, "bem pode provar ser um adjuvante efetivo na reabilitação psiquiátrica".

O conceito de "lidar com" é central para a HVN, com base na crença da organização de que as pessoas se sentem melhor não quando suas vozes são erradicadas, mas quando a pessoa que ouve vozes aprende a escutar a alucinação sem angústia. Jacqui Dillon, diretora nacional da ROV, abraça esse credo baseada em sua experiência pessoal. Dillon, mãe de duas crianças, ouviu vozes por mais de trinta anos e nunca tomou medicação. Na maior parte do tempo, suas vozes são um apoio e mesmo espirituosas, apesar de ocasionalmente serem cruéis elas blasfemam e lhe dizem para se machucar. Porém ela não mais leva em consideração suas ordens nem permite que a aborreçam. Em vez disso, ela as considera símbolos de seus pensamentos inconscientes. "Algumas vezes, as vozes carregam mensagens que você não quer ouvir", disse-me ela. "No entanto, você não acaba com o mensageiro, você o escuta."

A pregação de Romme em favor da "aceitação" alucinatória emergiu no começo dos anos 1990; na época, originou forte reprovação no British Medical Journal, revista do mainstream médico. Revisando Aceitando as vozes (1993) uma miscelânea de achados de pesquisa, estratégias para lidar com vozes e testemunhos em primeira mão editada por Romme e sua esposa e colega, Sandra Escher -, Raymond Cochrane, professor de psicologia na Universidade de Birmingham, escreveu: "Algo que possa encorajar as pessoas a aceitarem a realidade de suas crenças delirantes, e até mesmo atribuir a elas algum poder místico sobrenatural, pode apenas prolongar a existência destas crenças e fazer com que a recuperação da esquizofrenia seja mais demorada e incerta."

Mas o trabalho de Romme influenciou um certo número de pesquisadores e clínicos, mesmo aqueles que não estavam inclinados a militar em prol da libertação dos que ouvem vozes. "No final dos anos 1980, ouvir vozes tornouse uma experiência estigmatizada, as pessoas esqueceram que não é apenas o 


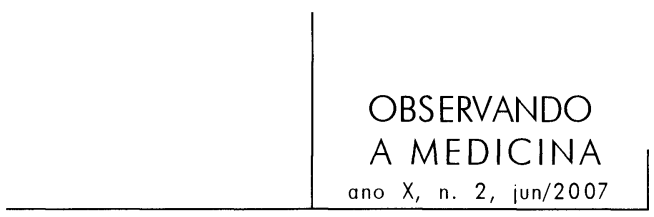

insano que ouve vozes", diz Douglas Turkington, psiquiatra da Enfermaria Royal Victoria, em Newcastle. "A norma era: "Não fale com os pacientes sobre a experiência. Isso só piora as coisas'.” O relato de Romme de que havia muitas pessoas vivendo na comunidade que ouviam vozes e não se afligiam, diz Turkington, forneceu a base para uma abordagem psicoterapêtica da esquizofrenia em que ele e um colega, David Kingdon, professor de psiquiatria na Universidade de Southampton, já estavam envolvidos. Adaptando as técnicas da terapia cognitivo-comportamental, eles começaram no final dos anos 1980 a conduzir os pacientes, por meio de um questionamento de tipo socrático, para um entendimento de suas alucinações como vindas de suas próprias mentes. A terapia incluía atenuar o medo da loucura dos pacientes, apontando que mesmo as pessoas "normais" podem ouvir vozes. Os esforços de Turkington e Kingdon são agora amplamente reconhecidos por terem ajudado a reabrir a porta para as abordagens psicoterapêuticas dos sintomas psicóticos.

Richard Bentall, professor de psicologia da Universidade de Manchester, acatou não apenas as implicações clínicas da pesquisa de Romme, mas também um pouco de seu ativismo político. Nos últimos 15 anos, Bentall ficou conhecido como um opositor dos diagnósticos da psiquiatria tradicional e como apoiador entusiástico das terapias baseadas no consumidor. No início dos anos 1990, como professor na Universidade de Liverpool, Bentall apoiou o primeiro grupo da HVN naquela cidade, e em agosto passado ele se reuniu a Romme e à ROV em uma conferência de imprensa que anunciou a Campanha pela Abolição do Rótulo da Esquizofrenia, por eles classificada como "o último grande movimento pelos direitos civis".

Para Bentall, esquizofrenia é um diagnóstico que equivale à tenda de um circo - abriga uma multidão heterogênea de experiências e serve para estigmatizar os pacientes. Os clínicos, afirma ele, deveriam tratar sintomas individuais e não síndromes. Ele não está simplesmente se entregando a um tipo de retórica dos antipsiquiatras dos anos 1960 e 1970, com os quais ele é algumas vezes comparado. Questionar a validade da esquizofrenia como um rótulo não é novo - mesmo os arquitetos do DSM reconhecem que ele é útil somente à medida que guia a pesquisa e o tratamento. E, enquanto o argumento de Bentall de que os sintomas psicóticos específicos deveriam ser estudados em relação aos mecanismos psicológicos que os origina o coloca fora da corrente principal, ele freqüentemente publica nas melhores revistas especializadas e é muitas vezes citado por psicólogos (que são mais inclinados do que os psiquiatras a colocar as alucinações auditivas no continuum da experiência do dia-a-dia). Ele também recebeu apoio do governo britânico para seu trabalho clínico; mais recentemente financiamento de \$2,9 milhões do Conselho de Pesquisa Médica do Reino Unido para investigar se a TCC pode evitar que pessoas que exibem sinais precoces de psicose desenvolvam completamente o transtorno. 


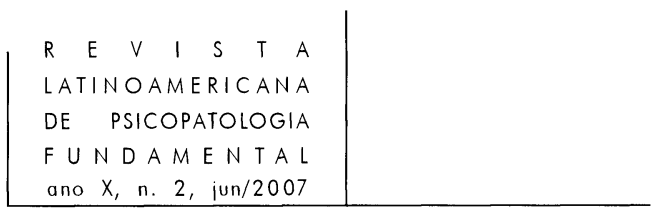

Em seu livro de 2003, A loucura explicada, Bentall apresenta a teoria de que as alucinações auditivas podem ter suas raízes naquilo que os psicólogos chamam "fala interna". Todos nós, todos os dias, produzimos uma corrente constante de fala silenciosa, dirigida para dentro: planos, pensamentos, citações, lembranças. As pessoas ouvem vozes, afirma Bentall, quando fazem julgamentos errôneos sobre se sua fala interna é o produto de sua própria consciência ou de algo alheio a ela. Lapsos no que os pesquisadores chamam de "monitoramento da fonte" podem acontecer por diversas razões - porque um indivíduo está preparado para esperar a ocorrência de uma percepção, porque o nível de ruído de fundo torna difícil separar o que é interno do que é externo, porque ele ou ela está em um estado de excitação emocional. Mas qualquer que seja a causa, escreve Bentall, há evidência sugerindo que alucinar "pode ser explicado em termos dos mesmos tipos de processos mentais que afetam os julgamentos perceptivos normais".

Essa teoria levanta a questão de porque o erro no monitoramento da fonte resulta em psicose: por que, quando as pessoas tomam sua fala interna pela de uma outra pessoa, isso as faz ficar tão angustiadas que procuram ajuda profissional? A resposta que Bentall oferece acompanha a observação de Romme de que uma diferença fundamental entre os que ouvem vozes e não estão sob cuidados psiquiátricos e os que ouvem vozes e estão sob cuidados psiquiátricos é que os últimos pensam negativamente sua experiência. Segundo Bentall, o modo como os pacientes percebem suas alucinações auditivas pode ter um impacto significativo sobre como essas alucinações são experimentadas. Bentall cita um estudo marcante de 1994 realizado por Max Birchwood, na Universidade de Birmingham, e Paul Chadwick, do Hospital Royal South Hants em Southampton, para apoiar esta posição. Publicado em The British Journal of Psychiatry, ele propõe que a angústia experimentada pelos pacientes que ouvem vozes está diretamente relacionada à crença na malevolência e no poder das vozes. Um estudo mais recente, publicado em 2004 e conduzido por Anthony Morrison, colega de Bentall na Universidade de Manchester, também concluiu que as crenças negativas sobre as vozes estão associadas a um aumento na angústia da experiência, e freqüentemente essas crenças negativas são reforçadas pelos serviços de saúde mental e pela mídia.

Segundo Louise Johns, psicóloga do Instituto de Psiquiatria de Londres, os modelos cognitivos da psicose tiveram um impacto importante na prática da saúde mental na Grã-Bretanha. Poucos psicólogos pensaram na TCC como uma panacéia; ela é tida como um adjuvante e não um substituto da intervenção médica padrão, mais freqüentemente em casos em que os pacientes não respondem bem à medicação ou estão cronicamente doentes. Desde o início dos anos 1990, mais de vinte experimentos clínicos aleatórios foram realizados com a TCC para a 


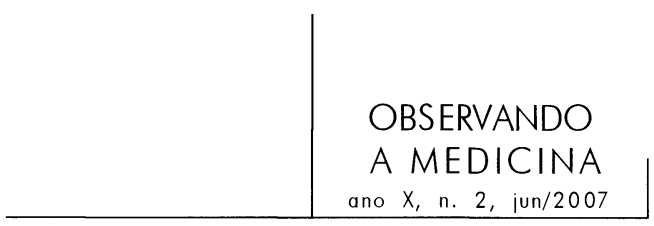

psicose, mostrando que a TCC pode ser útil no auxílio a pacientes que enfrentam sintomas psicóticos, aumentando a compreensão sobre a psicose e promovendo a obediência à medicação. Baseado nos achados desses estudos, o Instituto Nacional para a Saúde e Excelência Clínica - o corpo consultivo do Serviço de Saúde Mental Britânico - anunciou que a todos os "indivíduos com esquizofrenia que experimentam sintomas psicóticos persistentes deve ser oferecida a TCC”.

Membros da HVN exprimem uma apreciação cautelosa sobre esses desenvolvimentos. Muitos estão contentes com o fato de que profissionais da saúde mental estejam levando a sério a abordagem psicológica da psicose (sua literatura mostra inclusive o aumento da disponibilidade de terapia cognitivocomportamental), mas se preocupam com o fato de que a mensagem mais radical da organização esteja sendo obscurecida. Como sempre, diz Jacqui Dillon, a diretora da HVN, a mainstream está considerando mais o que os cientistas têm a dizer sobre como tratar o ouvir vozes do que aquilo que os não-cientistas como ela têm a dizer sobre como aceitar o fenômeno.

Era quase meio-dia de uma suave sexta-feira de janeiro quando o grupo de ouvintes de vozes de North Finchley se reuniu novamente após um intervalo de 15 minutos. Um sexto participante se juntou a eles: Chris, cabelos claros, acima do peso e com uma respiração audivelmente curta, membro há quatro anos. Ele parecia completamente à vontade.

Mais cedo naquele dia, Kutchinsky e Kaiser imprimiram uma lista de estratégias para lidar com vozes que membros de um outro grupo achou útil, colocando cada descrição em estreitos retângulos, que agora se espalham pela mesa, virados para baixo. Pediu-se para os participantes escolherem um e discutirem. Ângelo pegou o primeiro: "Hobbies". Ele limpou a garganta e, com uma voz suave e uniforme, começou: "Colecionar, ter aulas diurnas ou noturnas, visitar uma biblioteca, habilidades na informática, leitura e esporte. Todas estas atividades não são apenas divertidas e relaxantes; elas podem preencher vazios em nossas vidas e ajudar a nos ocupar durante o dia ou à noite. Elas podem aumentar a concentração e reduzir o isolamento. Podem também elevar nossa moral e confiança e nos dar um fator de bem-estar". Ao final, Ângelo levantou sua cabeça do papel e olhou em volta.

"Bem, você tem algum hobby, Ângelo?", perguntou Kutchinsky.

"Eu gosto de jogar xadrez", disse ele. "E, como eu disse, gosto de ler. Mas é difícil. Só consigo agüentar alguma coisa leve ou de humor. Como Dave Barry."

"Entendo. A leitura ajuda a bloquear completamente as vozes?"

Os olhos do Ângelo pareceram escurecer. "Não, acho que nada pode bloquear completamente as vozes. Mesmo quando eu toco uma música muito alta, isso não ajuda nada." 


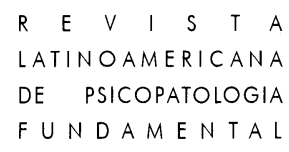

As estratégias que foram sendo apresentadas eram da mesma espécie da primeira - sugestões de senso comum para aumentar a organização da mente de alguém ou para mitigar os efeitos da experiência. Liana escolheu "Exercício"; Jenny escolheu "Atividades religiosas"; David escolheu "Mime-se" ("Ponha uma boa música na sala ao lado, espalhe algumas velas perfumadas pela sala. Você pode mesmo tomar banho com seu companheiro!"). A estratégia mais inusitada, e a única que pareceu animar os membros do grupo veio com os "Celulares". "Se você ficar tentado a gritar com as suas vozes em público, a sugestão é que o faça com um telefone em seu ouvido. Desta forma você pode-se sentir livre para deixar rolar, e ninguém que presencie isto vai pensar que você é louco". Chris em particular pareceu concordar com a sugestão. "Algumas vezes falo com minhas vozes em público", disse ele simplesmente. "É muito perturbador. Tenho que morder as articulações de meus dedos para suprimir a urgência."

Os participantes dos grupos de auto-ajuda se beneficiam de estratégias como estas porque abordam as vozes como você abordaria qualquer outra experiência dolorosa, mas normal, como ansiedade ou estresse. Muitos dos membros do grupo de North Finchley, contudo, prosseguem com o tratamento medicamentoso ao lado das estratégias para lidar com vozes. Eles falam e ao mesmo tempo tomam remédios. Obviamente, como Kutchinsky me falou, eles algumas vezes falam sobre as drogas. Falam sobre a melhor dosagem e sobre como lidar com a ansiedade, apatia e impotência que elas algumas vezes causam. Não há, sem dúvida, nada de errado com esta combinação. Pode ser até mesmo ideal: quem melhor para falar sobre a medicação do que as pessoas que realmente a consomem? E se você lutasse com uma experiência tão complicada quanto ouvir vozes, por que você não usaria todos os meios à sua disposição para lidar com isto?

Como para Ângelo, sua preocupação não é escolher uma opção ou outra mas apenas se recuperar. "Achei o grupo interessante", escreveu Ângelo via email três semanas depois de nos conhecermos. "Ele me fez perceber que muitos ouvintes de vozes têm tido esse problema por anos, e que muitos talvez nunca parem de ouvi-las, apesar de alguns terem êxito em relação a isso. Uma senhora deixou recentemente o grupo já que não mais ouvia vozes. Também vejo que alguns ouvintes de vozes são altamente funcionais e são capazes de manter um emprego apesar das vozes. Espero eu fazer isso. Talvez a combinação correta de drogas torne isto possível."

Daniel B. Smith é o autor de Muses, Madmen e Prophets: Rethinking the History, Science and Meaning of Auditory Hallucination, recém-publicada pela Penguin Press e a partir do qual este artigo foi em parte adaptado. 